\title{
Greater protection against oxidative damages imposed by various environmental stresses in transgenic potato with higher level of reduced glutathione
}

\author{
Amin Elsadig Eltayeb ${ }^{1,3)}$, Shohei Yamamoto ${ }^{1)}$, Mohamed Elsadig Eltayeb Habora ${ }^{1)}$, Yui Matsukubo' \\ Mitsuko Aono' ${ }^{2)}$, Hisashi Tsujimoto ${ }^{4)}$ and Kiyoshi Tanaka*1,3) \\ 1) Laboratory of Plant Biotechnology, Faculty of Agriculture, Tottori University, 4-101 Koyama, Tottori 680-8553, Japan \\ 2) Environmental Biology Division, National Institute for Environmental Studies, Onogawa, Tsukuba, Ibaraki 305-8506, Japan \\ 3) Arid Land Research Center, Tottori University, 1390 Hamasaka, Tottori 680-0001, Japan \\ 4) Laboratory of Plant Genetics and Breeding, Faculty of Agriculture, Tottori University, 4-101 Koyama, Tottori 680-8553, Japan
}

\begin{abstract}
Potato (Solanum tuberosum L.) is the world's number one non-cereal food crop and ranks fourth among most important crops grown worldwide in terms of acreage, yield and value. In order to maintain greater protection against environmental stresses, we developed transgenic potato overexpressing Arabidopsis thaliana glutathione reductase gene (AtGR1). The transgenic potato maintained up to 6.5 folds higher GR activity, 5.8 folds glutathione (GSH) contents and up to 2.2 folds higher glutathione $S$-transferase activity compared to non transformed plants (NT). Interestingly, while the transgenic plants exhibited decreased dehydroascorbate reductase (DHAR) activity, the relative reduced ascorbate (AsA) contents were higher while the relative dehydroascorbate (DHA) were lower compared to NT which provide a support to the hypothesis that an active glutathione-independent pathway for DHA reduction might exists in vivo. The transgenic plants maintained an enhanced tolerance to methylviologen, and cadmium. When subjected to drought stress, the transgenic plants exhibited faster recovery with less visual injury compared to NT. These results suggest that manipulation of glutathione levels provides reliable strategy for the development of industrial transgenic potato plants with enhanced tolerance to multiple environmental stresses.
\end{abstract}

Key Words: glutathione, ascorbate, oxidative stress, potato.

\section{Introduction}

Environmental stresses such as drought and heavy metals are known to accelerate the accumulation of reactive oxygen species (ROS) in plant cells. ROS such as singlet oxygen $\left(\mathrm{O}_{2}{ }^{1}\right)$, superoxide radical $\left(\mathrm{O}_{2} \cdot\right)$, hydrogen peroxide $\left(\mathrm{H}_{2} \mathrm{O}_{2}\right)$ and hydroxyl radical $(\mathrm{OH} \cdot)$ are capable of unrestricted oxidation of many cellular components and can lead to oxidative destruction of the cell (Asada and Takahashi 1987, Mittler 2002). Detoxification of ROS in plant cells is accomplished by enzymatic and non-enzymatic scavenging systems. Low molecular weight antioxidants such as ascorbate (AsA) and glutathione (GSH) are of paramount importance in preventing and controlling the dangerous affects of ROS (Noctor and Foyer 1998). Among antioxidative enzymes, monodehydroascorbate reductase (MDAR), dehydroascorbate reductase (DHAR) and glutathione reductase (GR) are particularly important due to their roles in catalyzing redox reactions and maintaining reduced pools of AsA and GSH in the AsA-GSH pathway (Noctor and Foyer 1998). GSH, the tripeptide $\gamma$-glu-cys-gly, is an abundant and ubiquitous non-

Communicated by M. Ohshima

Received November 20, 2009. Accepted March 1, 2010.

*Corresponding author (e-mail: jotanaka@muses.tottori-u.ac.jp) protein thiol in most plant cells (Bergman and Rennenberg 1993, Noctor and Foyer 1998). The physiological significance of GSH in plant cells includes sulphur metabolism, detoxification of xenobiotic compounds (Potters et al. 2002, Noctor and Foyer 1998), regulation of gene expression and the redox regulation of cell cycle (Noctor et al. 1998). GSH exists interchangeably with the oxidized form GSSG in the AsA-GSH cycle. GR catalyses the NADPH-dependent reduction of GSSG to GSH. Various studies using transgenic plants have shown the importance of GR in the defense against oxidative stress caused by various environmental stresses such as photoinhibition (Aono et al. 1993, 1995, Foyer et al. 1995) and heavy metal toxicity (Pilon-Smits 2000, Xiang et al. 2001). Noctor et al. (1998) have extensively reviewed several studies showing the importance of GR in the defense against oxidative stress. In contrast, an increased sensitivity to oxidative stress in transgenic plants with elevated GSH levels by either overexpression of $\gamma$ glutamylecysteine synthetase ( $\gamma$-ECS), glutathione synthetase (GS) or GR has been also reported (Creissen et al. 1999, Logan et al. 2003).

Potato (Solanum tuberosum L.) is the world's number one non-cereal food crop, with total production reaching a record of 325 million tonnes in 2007 (FAOSTAT, http:// www.faostat.fao.org). Due to its high productivity, starch 
and vitamin contents, potato ranks fourth among most important crops grown worldwide in terms of acreage, yield and value (FAOSTAT). Extensive efforts to improve potato have been carried with regards to quality and resistance to pathogens. Improving potato with greater protection against abiotic stresses through molecular breeding technologies remains generally limited (Tang et al. 2006). In particular, few researches to incorporate genes for antioxidative enzymes into potato plants have been conducted. Enhancement of oxidative stress tolerance have been reported in transgenic potato overexpressing $\mathrm{Cu} / \mathrm{Zn}$ superoxide dismutase gene (Perl et al. 1993), class II catalase ( $\mathrm{Yu}$ et al. 1999), both $\mathrm{Cu} / \mathrm{Zn}$ SOD and ascorbate peroxidase (Tang et al. 2006) and nucleoside diphosphate kinase 2 (Tang et al. 2008). Recently, Goo et al. (2008) have characterized the expression of DHAR gene in leaves of transgenic potato and suggested that increased DHAR activity was not always accompanied by elevation in AsA and other factors might limit accumulation of AsA.

In this study, we report the generation of transgenic potato overexpressing Arabidopsis cytosolic GR1 gene. While Arabidopsis AtGR2 is dual-targeted to chloroplasts and mitochondria and considered as essential for plant development (Tzafrir et al. 2004), AtGRl codes for the cytosolic isoform, reported to be responsive to several stress factors (Zimmermann et al. 2004) and constitutes the main GR activity in Arabidopsis (Marty et al. 2009). We further characterized the metabolic effects of GR overexpression in the AsA pool and the consequent gain or loss in the stress tolerance to, methylviologen (MV), drought and cadmium.

\section{Materials and Methods}

\section{Construction of plant expression vector}

The full length cDNA of the Arabidopsis thaliana AtGR1 (At3g24170) was amplified from Arabidopsis cDNA library by PCR using the primers cytGRGW-F 5'-GGCTTCACCA TGGCGAGGAAGATGATGCTTGTTGATGGTGA-3' and cytGRGW-R 5'-GAAAGCTGGGTCTCATAGATTTGTC TTAGGTTTGGGTTTGT-3' and the Primse-STAR ${ }^{\circledR}$ HS DNA Polymerase (Takara, Shiga, Japan). Transformation constructs were obtained with Gateway technology (Invitrogen, Carlsbad CA, USA). AtGR1 was cloned into pDONRTM/ Zeo using Gateway ${ }^{\circledR}$ BP Clonase ${ }^{\mathrm{TM}}$ II Enzyme Mix to generate an entry clone. An LR recombination reaction was performed using Gateway LR clonase II enzyme mix (Invitrogen) to shuttle AtGRl into the destination vector pGWB502 $\Omega$ (Nakagawa et al. 2007) under the control of a duplicated CaMV35S enhancer along with $\Omega$ translation enhancer from tobacco mosaic virus. This construct was introduced into Agrobacterium tumefaciens strain C58C1 and used for Agrobacterium-mediated gene transfer.

\section{Plant materials}

Potato plants (Solanum tuberosum L.) cv. Atlantic (USDA Plant Genetics and Germplasm Institute) were main- tained on Murashige and Skoog medium (Murashige and Skoog 1962) containing 2\% sucrose and $0.4 \%$ Phytagel (Sigma, St. Louis, USA) in a growth chamber at $22^{\circ} \mathrm{C}$ under a $16 \mathrm{~h}$ light cycle and $60 \% \mathrm{RH}$.

\section{Agrobacterium-mediated transformation of potato plants}

Leaves were excised from four-week old healthy plants, wounded and infected with Agrobacterium infection medium as described by Banerjee et al. (2006). Callus was induced on medium consisted of MS salts and vitamins, $16 \mathrm{gl}^{-1} \quad$ glucose, $\quad 5 \mathrm{mgl}^{-1} \quad \alpha$-naphthaleneacetic acid (NAA), $0.1 \mathrm{mg} \mathrm{l}^{-1}$ 6-Benzylaminopurine (BAP), $250 \mathrm{mg} \mathrm{l}^{-1}$ cefotaxime (Sanofi Aventis, Tokyo, Japan), $5 \mathrm{mg} \mathrm{l}^{-1}$ hygromycin (Roche, Mannheim, Germany) for 10 days in a growth chamber at $25^{\circ} \mathrm{C}, 16 \mathrm{~h}$ light, $8 \mathrm{~h}$ dark photoperiod. Shoots were induced on MS salts and vitamins medium supplied with $20 \mathrm{~g} \mathrm{l}^{-1}$ sucrose, $2.2 \mathrm{mg} \mathrm{l}^{-1}$ zeatin-riboside, $0.02 \mathrm{mg} \mathrm{l}^{-1}$ NAA, $0.15 \mathrm{mg} \mathrm{l}^{-1}$ gibberellic acid (GA3), $250 \mathrm{mg} \mathrm{l}^{-1}$ cefotaxime, $5 \mathrm{mg} \mathrm{l}^{-1}$ hygromycin for 4 weeks. Emerging shoots $2-3 \mathrm{~cm}$ in length were transferred to root induction medium consisted of MS salts and vitamins, $20 \mathrm{~g} \mathrm{l}^{-1}$ sucrose, $250 \mathrm{mg} \mathrm{l}^{-1}$ cefotaxime and $5 \mathrm{mg} \mathrm{l}^{-1}$ hygromycin. Plants with developed roots were then transplanted on a vermiculite and maintained under controlled conditions $\left(25^{\circ} \mathrm{C}, 16 \mathrm{~h}\right.$ light, $8 \mathrm{~h}$ dark photoperiod).

\section{Genomic PCR and RT-PCR}

The presence of $A t G R 1$ in the genome of transgenic potato plants was confirmed by PCR using GR-RT-F 5'-CATTTCACCCTATTAGCTCTG-3' and GR-RT-R 5'CTTCGCTGAGACCCACTACAG-3' and Go Taq ${ }^{\circledR}$ Green Master Mix (Promega, Madison, USA) according to manufacture instructions. To carry the reverse transcriptase polymerase chain reaction (RT-PCR), total RNA was isolated from leaf tissues using TriPure Isolation Reagent (Roche, Mannheim, Germany) and treated with RNase-free DNase I to remove any contamination with genomic DNA. One $\mu \mathrm{g}$ total RNA was used to synthesize a first stand cDNA using Transcriptor First Strand cDNA Synthesis Kit (Roche) according to manufacture instructions. One $\mu \mathrm{l}$ of first strand cDNA reaction was subjected to a PCR using GR-RT-F and GR-RT-R primers while actin was amplified using actinRT-F 5'-TGGACTCTGGTGATGGTGTC-3' and actin-RTR 5'-CCTCCAATCCAAACACTGTA-3' as described by Tang et al. (2006).

\section{GR activity staining}

Leaf samples $(0.1 \mathrm{~g})$ from transgenic potato, NT plants and Arabidopsis were frozen in liquid nitrogen and grounded to powder with a pre-cooled mortar and pestle, homogenized in $50 \mathrm{mM}$ potassium phosphate buffer ( $\mathrm{pH} 7.8$ ) containing $1 \mathrm{mM}$ ascorbate and $2 \%(\mathrm{w} / \mathrm{v})$ polyvinylpolypyrrolidone (PPVP). The homogenate was centrifuged at $15000 \mathrm{rpm}$ at $4{ }^{\circ} \mathrm{C}$ for $25 \mathrm{~min}$ and the supernatant was used for enzyme activities. Activity staining of GR was carried as described by Foyer et al. (1991). Extracted proteins were 
separated on a $10 \%(\mathrm{w} / \mathrm{v})$ native gel then incubated for $15 \mathrm{~min}$ in $25 \mathrm{ml}$ of $250 \mathrm{mM}$ Tris- $\mathrm{HCl}(\mathrm{pH} 8.4), 4 \mathrm{mM} \mathrm{GSSG}$, $1.5 \mathrm{mM}$ NADPH and $2 \mathrm{mM}$ DTNB (5,5-dithiobis-(2nitrobenezonic acid)). Total protein was determined according to Bradford (1976).

\section{GR, DHAR and GST activities}

All enzyme activities were measured sepctrophotometrically using Ultrospec 2100 pro (Biochrom, Cambridge, UK). GR was assayed according to Tanaka et al. (1988) by monitoring the GSH-dependent oxidation of NADPH at $340 \mathrm{~nm}$ in $50 \mathrm{mM}$ potassium phosphate buffer ( $\mathrm{pH} 7.8$ ), $0.1 \mathrm{mM}$ EDTA, $0.2 \mathrm{mM}$ NADPH, $0.2 \mathrm{mM}$ GSSG and crude extracts. GR activity was calculated using absorbance coefficient of $6.2 \mathrm{mM}^{-1} \mathrm{~cm}^{-1}$. DHAR was assayed as described previously (Eltayeb et al. 2006) in reaction mixture contained $50 \mathrm{mM}$ potassium phosphate, $2 \mathrm{mM}$ dehydroascorbate (DHA), $5 \mathrm{mM}$ GSH and crude extract. The increase in absorbance at $290 \mathrm{~nm}$ due ascorbate was monitored and the activity was calculated using absorbance coefficient of $2.8 \mathrm{mM}^{-1} \mathrm{~cm}^{-1}$. GST was assayed as described by (Alla et al. $2007)$ with slight modification. The reaction mixture consisted of $50 \mathrm{mM}$ potassium phosphate buffer $(\mathrm{pH} 7.8)$, $0.1 \mathrm{mM}$ EDTA, $5 \mathrm{mM}$ GSH, $1 \mathrm{mM}$ chlorodinitrobenzene (CDNB) and crude extracts. The reaction was monitored at $340 \mathrm{~nm}$ and the enzyme activity was calculated using extinction coefficient of $9.2 \mathrm{mM}^{-1} \mathrm{~cm}^{-1}$.

\section{AsA, DHA, GSH and GSSG contents}

Leaf samples $(0.3 \mathrm{~g})$ were homogenized in $2 \mathrm{ml}$ of $5 \%$ $(\mathrm{w} / \mathrm{v})$ metaphosphoric acid, centrifuged at $15000 \mathrm{rpm}$ at $4^{\circ} \mathrm{C}$ for $20 \mathrm{~min}$ and aliquots of the supernatant were used to for the measurements. Ascorbate contents were determined following Shigeoka et al. (1987) with slight modification. Two aliquots were used in separate assays for total ascorbate (AsA+DHA) and DHA. An aliquot of $0.15 \mathrm{ml}$ of $6 \mathrm{mM} 2,6-$ dichloroindophenol (DCIP) was added into the supernatant for the assay of total ascorbate, while it was replaced by the same volume of distilled water for the assay of oxidized ascorbate. After keeping the mixtures of the two assays at room temperature for $20 \mathrm{~min}$, aliquots of $0.15 \mathrm{ml}$ of $1 \%$ $(\mathrm{w} / \mathrm{v})$ thiourea in $5 \%$ metaphosphoric acid and $0.15 \mathrm{ml}$ of $10 \mathrm{mM}$ 2,4-dinitrophenyldazine (DNPH) were added. The mixtures were then incubated at $50^{\circ} \mathrm{C}$ for $1 \mathrm{~h}$, cooled in an ice bath for $15 \mathrm{~min}$ while adding $0.375 \mathrm{ml}$ of ice-cold $85 \%$ (v/v) of $\mathrm{H}_{2} \mathrm{SO}_{4}$. An aliquot of $0.15 \mathrm{ml}$ of $20 \%(\mathrm{v} / \mathrm{v}) \mathrm{H}_{2} \mathrm{SO}_{4}$ was added and then the absorbance at $520 \mathrm{~nm}$ was measured. AsA content was calculated by subtracting oxidized ascorbate from total ascorbate. GSH and GSSG were measured according to Griffith (1980).

\section{$M V$, drought and heavy metal treatments}

Leaf discs ( $7 \mathrm{~mm}$ in diameter) were soaked in either distilled water or $3 \mu \mathrm{M}$ methylviologen for 0,12 or $24 \mathrm{~h}$ at $25^{\circ} \mathrm{C}$. Ion leakage was measured as an increase in the conductance of the floating solution using Horiba B-173 con- ductivity meter (Horiba, Kyoto, Japan). To estimate the total ion content of the tissue, discs were autoclaved after the experiment and the conductivity of the resulting solution was determined. Drought stress treatment was carried using transgenic potato and NT growing in soil by withholding irrigation water completely for one week then irrigated for a two days recovery period in a growth chamber under $25^{\circ} \mathrm{C}$, $16 \mathrm{~h}$ light, $8 \mathrm{~h}$ dark photoperiod. To carry the heavy metal stress treatment, part of the potato seedlings $(2 \mathrm{~cm})$ were excised and transferred to MS medium supplied with $200 \mu \mathrm{M}$ $\mathrm{CdCl}_{2}$ and maintained for 30 days under controlled conditions $\left(25^{\circ} \mathrm{C}, 16 \mathrm{~h}\right.$ light, $8 \mathrm{~h}$ dark photoperiod), then the length of the induced roots and the stem elongation were measured.

\section{Statistical analysis}

Data points represent the mean of three replications. Data were analyzed using Student's $t$-test at 95\% confidence limit.

\section{Results}

\section{Generation of GR overexpressing transgenic potato}

The cDNA of $A$. thaliana cytosolic AtGR1 under the control of a duplicated CaMV35S enhancer along with $\Omega$ translation enhancer from tobacco mosaic virus and upstream of

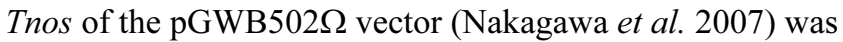
mobilized into Agrobacterium tumefaciens strain C58C1 and used for Agrobacterium-mediated gene transfer of potato plants. Three hygromycin resistant potato lines (designated as GR2, GR6 and GR11) were regenerated. DNA isolated from the leaves of the regenerated lines and from NT plants was used for genomic PCR analysis that confirmed the presence of $A t G R 1$ in the genome of the three lines (Fig. 1A). RT-PCR analysis using AtGRl specific primers and RNA isolated from potato transgenic lines and NT plants was carried to confirm the expression of AtGR 1 transgene. Although a band corresponding to potato native GR gene was not detected in NT plants due to the primer specificity to AtGR1, enhanced expression of AtGRl was confirmed in all transgenic potato lines (Fig. 1B).

\section{Higher GR activity and GSH contents in transgenic potato}

Activity staining for GR using proteins isolated from both NT and transgenic potato plants detected a clear band corresponding to the cytosolic GR activity derived from AtGR 1 transgene in the extracts prepared from transgenic plants but not from NT (Fig. 2A). While a lower band corresponding to the chloroplastic GR was detected in all plants, the band corresponding to the native cytosolic GR was not detected, which might be due to the less abundance of the native cytosolic GR compared to the chloroplastic one. Two representative transgenic potato lines (GR2 and GR11) were chosen for further analysis.

GR enzyme assay was carried using extracts from NT and transgenic potato plants grown under normal growth conditions. Compared to NT plants, transgenic lines GR2 and 
A

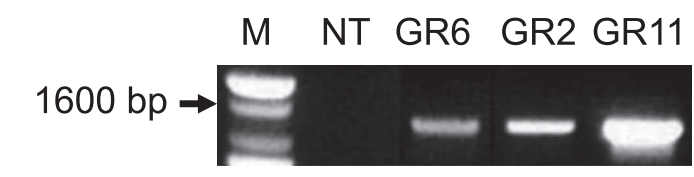

B

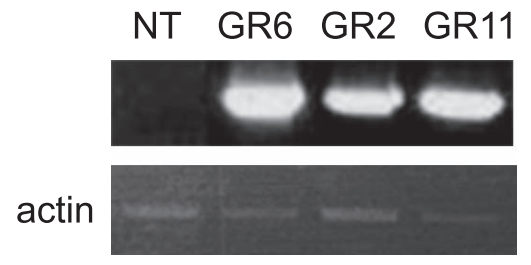

Fig. 1. Molecular analysis of transformed potato plants. (A) Detection of AtGRl transgene by PCR using genomic DNA isolated from GR6, GR2 and GR11 transgenic potato lines and NT. M, molecular weight marker; NT, non transgenic potato plants. (B) Expression analysis by RT-PCR using total RNA isolated from GR6, GR2 and GR11 transgenic potato lines and NT. Actin was used as a control for the equal loading. NT, non transgenic potato plants.

A

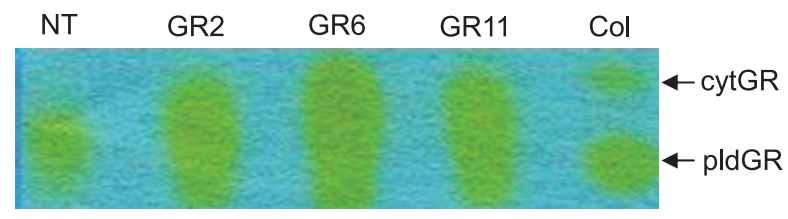

B

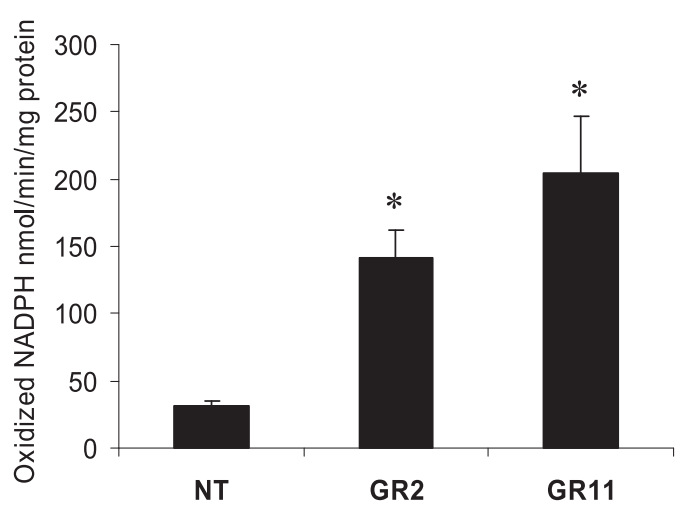

Fig. 2. GR activity staining and enzyme assay. (A) Activity staining for GR using proteins isolated from GR2, GR6 and GR11 transgenic potato and NT plants. cytGR, cytosolic GR; pldGR, chloroplastic GR; $\mathrm{Col}$, Arabidopsis plants cv. Columbia. (B) GR enzyme assay using extracts from GR2 and GR11 transgenic potato and NT grown under normal growth conditions. NT, non transgenic potato plants; ${ }^{*}, P<0.05$. Vertical bars represent the SE of the mean from triplicate determinations.
A

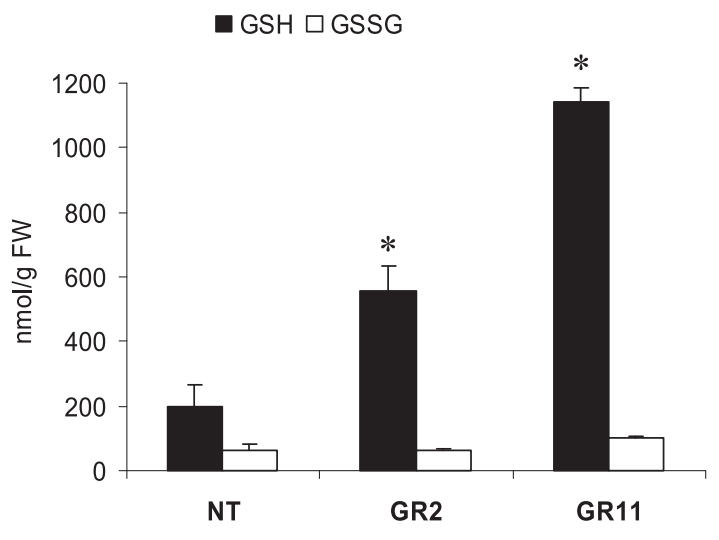

B

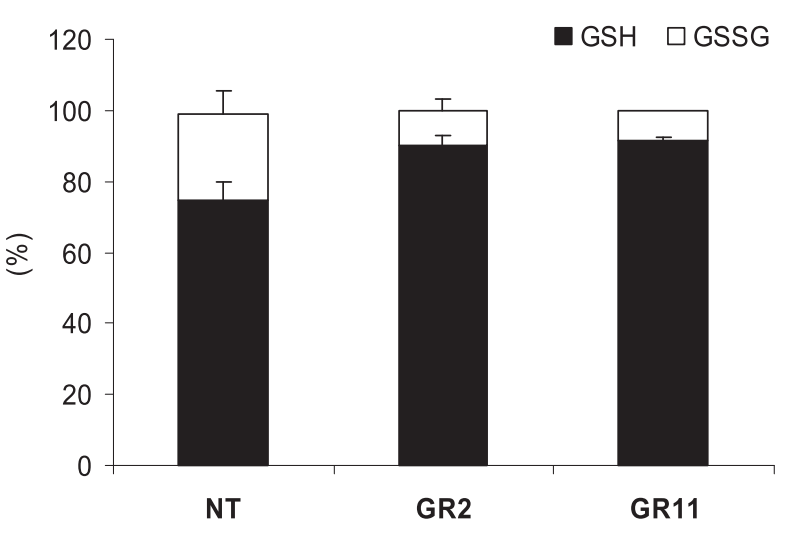

Fig. 3. GSH contents and the relative contents of GSH and GSSG. (A) GSH contents measured in the leaves of GR transgenic potato and NT plants. (B) The relative GSH contents in the leaves of GR transgenic potato and NT plants. GR2, GR11, transgenic potato; NT, non transgenic potato plants; *, $P<0.001 P<0.05$. Vertical bars represent the $\mathrm{SE}$ of the mean from triplicate determinations.

GR11 exhibited increased GR activity up to 4.5 and 6.5 folds, respectively (Fig. 2B).

To determine the metabolic consequences of GR overexpression, we measured the contents of GSH and GSSG present in leaves of transgenic potato and NT plants. Compared to NT, the transgenic lines GR2 and GR11 showed higher GSH contents up to 2.8 and 5.8 folds, respectively (Fig. 3A). The contents of GSH in GR2 and GR11 represented 91.7 and $89.9 \%$ of the total glutathione pool contents compared to $74.5 \%$ in NT plants (Fig. 3B).

GST and DHAR activities and the redox status of ascorbate

Enzyme assays were carried using leaf crude extracts from NT and transgenic potato plants. Compared to NT plants, GR2 and GR11 exhibited higher GST activity up to 1.9 and 2.2 folds, respectively (Fig. 4). GST expression has been reported to be induced in response to wounding (Marrs 1996). Pathogenesis related proteins are also reported to be induced by stresses such as cutting and injury (Ohashi and 


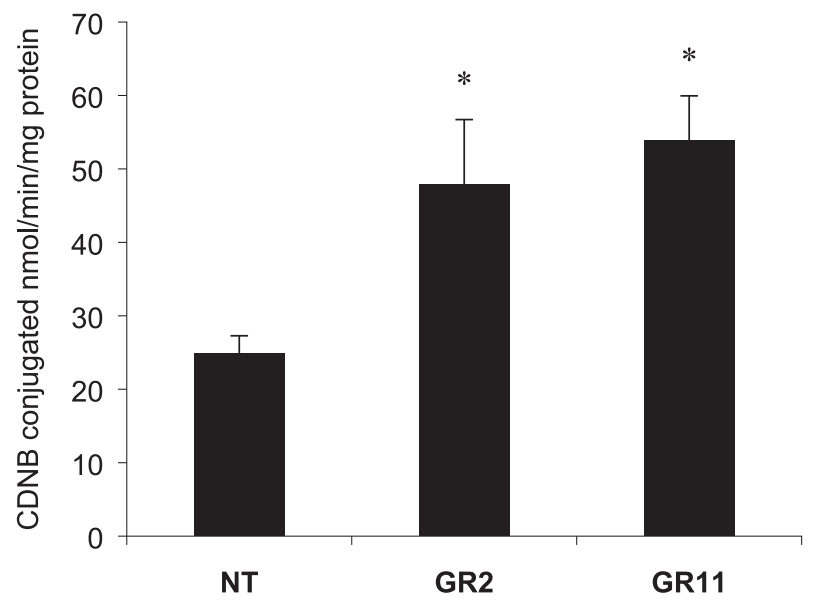

Fig. 4. GST enzyme activity measured in the leaves of GR transgenic potato and NT plants. GR2, GR11, transgenic potato; NT, non transgenic potato plants; *, $P<0.05$. Vertical bars represent the SE of the mean from triplicate determinations.

Matsuoka 1985). To confirm that our experimental procedure is free from any wounding or injury stress that may affect GST induction, we analyzed the expression of StPR-1 by RT-PCR. The results showed no differences in StPR-1 expression between NT and transgenic plants (data not shown).

DHAR activity in GR2 and GR 11 was decreased by $20 \%$ and $59 \%$, respectively, compared to NT plants (Fig. 5A). The contents of total AsA were higher in NT plants by $13 \%$ and $11 \%$ compared to GR2 and GR11, respectively (Fig. 5B). Surprisingly, DHA contents were significantly lower in GR2 and GR11 by $40 \%$ and $58.9 \%$, respectively, compared to the level in NT plants (Fig. 5B). The relative contents of AsA were higher in GR transgenic plants where it represented 62.6 and $71.8 \%$ of the total ascorbate pool of GR2 and GR11, respectively, compared to $53.0 \%$ for NT plants (Fig. 5C).

\section{Ion leakage following MV treatment}

Treatment with MV causes the generation ROS and participate in the damage to plants (Asada and Takahashi 1987). Leaf discs from NT and GR transgenic potato were treated with $3 \mu \mathrm{M}$ MV. After $12 \mathrm{~h}$ of MV treatment, 50\% and 55\% of ion leakage were observed in GR2 and GR11, respectively compared to $65 \%$ in NT plants. When MV treatment was prolonged to $24 \mathrm{~h}$, the ion leakage was $70 \%$ for both GR2 and GR 11 compared to $80 \%$ in NT plants (Fig. 6).

\section{Visual injury and recovery from drought stress}

Both NT and transgenic potato grown on soil and similar in age and size were subjected to drought stress by withholding the irrigation water for one week then re-irrigated and allowed to recover for two days. GR transgenic potato showed better and rapid recovery from drought stress with less visual injury in the leaves and the stems as compared to NT plants (Fig. 7).
A

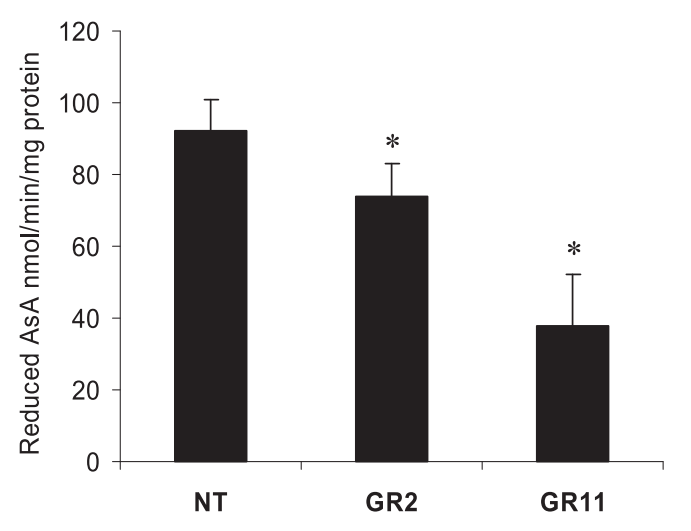

B

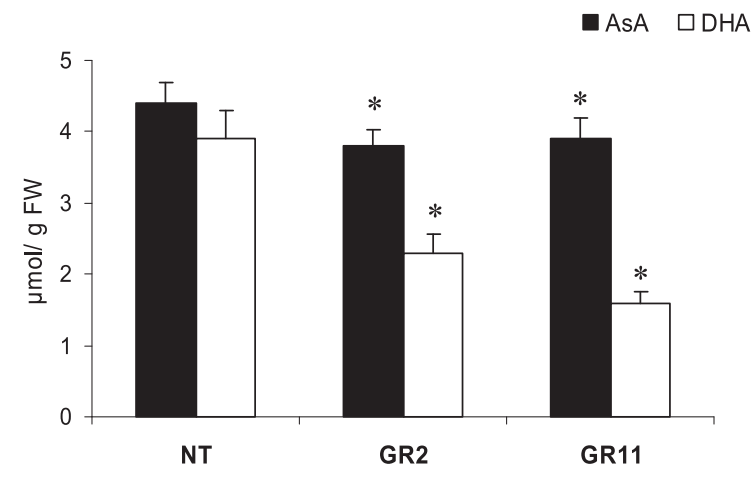

C

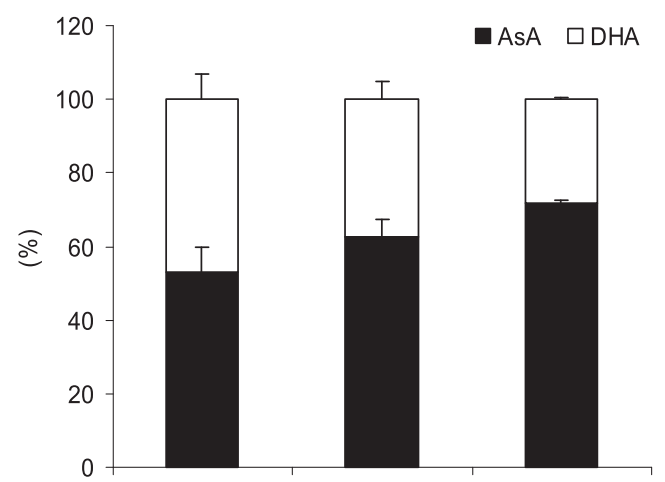

Fig. 5. DHAR activity, contents of AsA and the relative contents of AsA and DHA. (A) DHAR enzyme assay carried using leaf crude extracts from GR transgenic potato and NT plants. (B) Contents of AsA and DHA in leaves of GR transgenic potato and NT plants. (C) The relative contents of the reduced AsA and DHA. GR2, GR11, transgenic potato; NT, non transgenic potato plants; ${ }^{*}, P<0.05$. Vertical bars represent the SE of the mean from triplicate determinations.

\section{Root and shoot growth under cadmium stress}

An excised part of the seedlings $(2 \mathrm{~cm})$ from NT and transgenic potato was maintained in MS medium supplemented with $200 \mu \mathrm{M} \mathrm{CdCl} 2$ for 30 days. While no differences were observed in plant growth under control conditions, the growth of all plants was severely reduced due to the stress imposed by $\mathrm{CdCl}_{2}$, GR2 and GR11 transgenic potato lines extended significantly longer roots compared to NT 


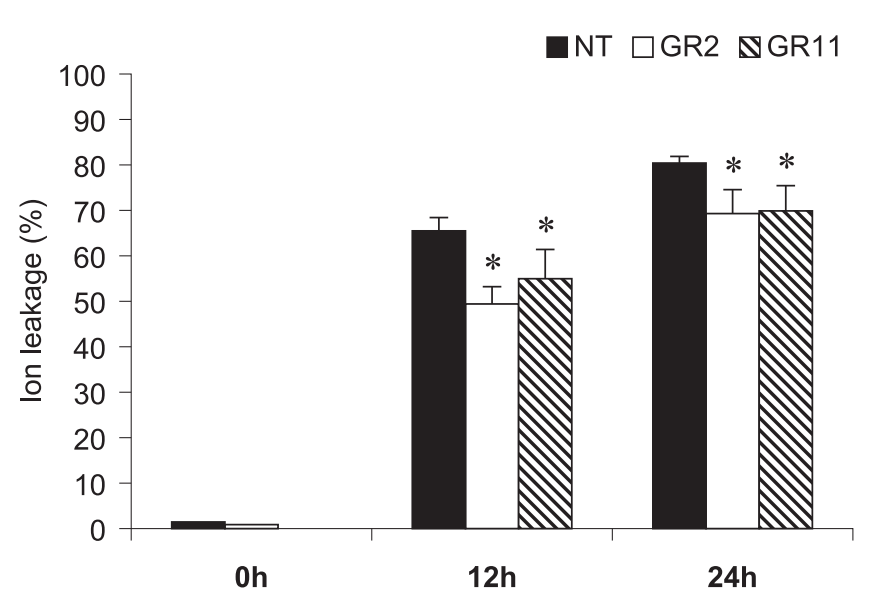

Fig. 6. Ion leakage measured in leaf discs from GR transgenic potato and NT. The leaf discs were soaked in $3 \mu \mathrm{M}$ methylviologen for 0,12 or 24 hours. GR2, GR11, transgenic potato; NT, non transgenic potato plants; *, $P<0.05$. Vertical bars represent the SE of the mean from triplicate determinations.
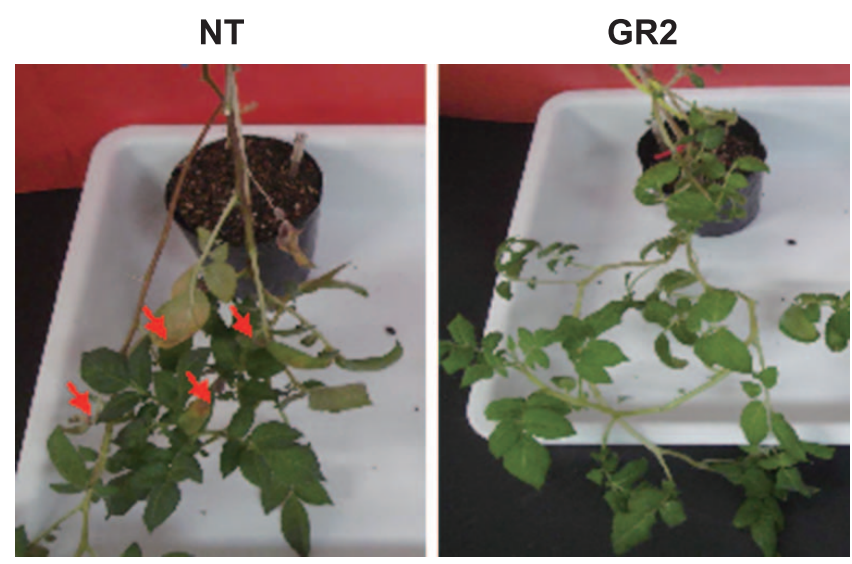

Fig. 7. Visual injury and recovery from drought stress of GR transgenic potato and NT. Plants grown on soil were subjected to drought stress by withholding the irrigation water for one week then reirrigated and allowed to recover two days period. GR2, transgenic potato; NT, non transgenic potato plants. Visual injury is indicated by red arrows.

plants (Fig. 8). In contrast, NT plants maintained slightly better shoot length compared to transgenic potato.

\section{Discussion}

In this study, we achieved up to 6.5 folds higher GR activity in the cytosol of transgenic potato (Fig. 2B) using a doubledenhancer 35S CaMV along with $\Omega$ translation enhancer from tobacco mosaic virus. Staining activity of the overexpressed cytosolic GR showed remarkable higher activity compared to the activity detected in NT and Arabidopsis plants (Fig. 2A) which indicate the stability of the Arabidopsis GR in the cytosol of transgenic potato. The GSH contents of the transgenic potato were up to 5.8 folds higher compared to that of the NT plants (Fig 3A), which could be attributed directly to the elevated GR activity and its stability

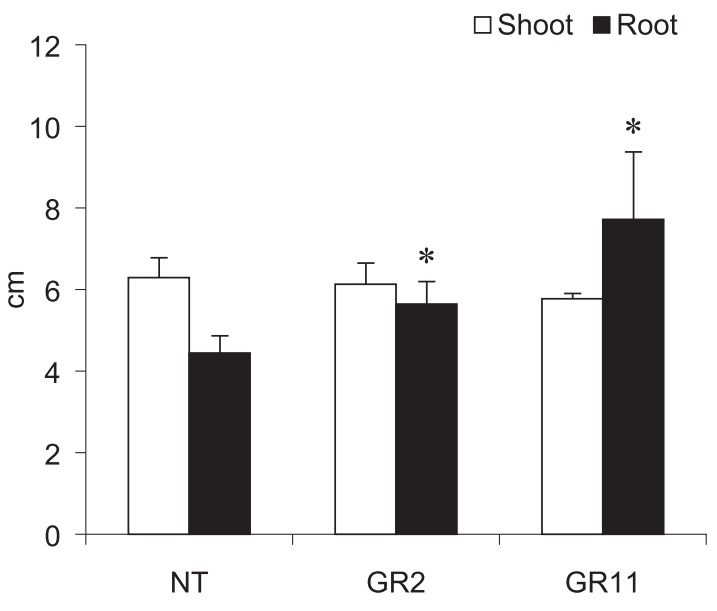

Fig. 8. Root and shoot growth under cadmium stress. GR transgenic potato and NT seedlings were cut $(2 \mathrm{~cm}$ length), transferred to MS medium supplemented with $200 \mu \mathrm{M} \mathrm{CdCl}_{2}$ for 30 days then the induced roots and shoot elongation length were measured. GR2, GR11, transgenic potato; NT, non transgenic potato plants; $*, P<0.05$. Vertical bars represent the SE of the mean from triplicate determinations.

in the transgenic potato lines. Similar GR activities were obtained in transgenic tobacco (Aono et al. 1991, Foyer et al. 1991) and transgenic poplar (Foyer et al. 1995) plants transformed with bacterial GR, while GSH contents was not affected in the poplar due to less stability of the bacterial GR in the cytosol (Foyer et al. 1995). As a result of GR overexpression, GSH contents in GR2 and GR11 represented 91.7 and $89.9 \%$ of the total glutathione pool compared to $74.5 \%$ in NT plants (Fig. 3B).

In this study, transgenic potato with overexpressed levels of GR showed an increased GST activity up to 2.2 folds compared to NT plants (Fig. 4). Theses results agreed with Mauch and Dudler (1993) who have demonstrated the induction of wheat GstA1 by addition of GSH. GSTs expression in plants is up-regulated in many different stress situations such as senescence and biotic elicitors and also in response to treatment with glutathione (Marrs 1996, Wagner et al. 2002). To confirm that GST induction in our transgenic potato is due to elevated GSH level, and not cutting or wounding stress during our experimental procedure, we carried RT-PCR analysis for StPR-1 expression. No differences were observed in the expression levels of $S t P R-1$, therefore, the elevated activity of GST in transgenic potato lines could be attributed only to the elevated levels of GSH.

At alkaline $\mathrm{pH}$ values, GSH rapidly reduces DHA to ascorbate in non-enzymatic reaction and in plant tissue this reaction is catalyzed by DHAR (Foyer and Halliwell 1976, Noctor et al. 1998). In order to observe the metabolic consequences of GR overexpression, we measured DHAR activity and the contents of the ascorbate pool. Surprisingly, the transgenic potato plants exhibited significantly decreased DHAR activity (Fig. 5A) and total ascorbate contents compared to NT plants (Fig. 5B). While these results appear to be in contradiction with the reports that showed higher 
ascorbate contents in transgenic plants overexpressing GR (Foyer et al. 1995), it come on line with recent findings that suggest the existence of an active GSH-independent pathway for DHA reduction (Potters et al. 2004). Moreover, different proteins have been proposed to carry out DHA reduction without using GSH in animals (Potters et al. 2002) and plant thioredoxins apparently show DHA reducing activity (Morell et al. 1997, Foyer and Mullineaux 1998). Additionally, other enzymes such as thioltransferases, protein disulphide isomerases and kunti-type trypsin inhibitor are also reported to catalyze the reaction between DHA and GSH (Wells et al. 1990, Trumper et al. 1994, Morell et al. 1997).

DHA can be reduced directly by reduced glutathione at alkaline $\mathrm{pH}$ values and also by enzymes that catalyse this conversion such as DHAR (Foyer et al. 1998). Despite the lower activity of DHAR, DHA contents were lower in the transgenic potato (Fig. 5B) and the relative AsA contents of the transgenic potato represented up to $71.8 \%$ of total ascorbate pool compared to $53 \%$ in NT plants (Fig. 5C). This might be attributed to the higher GSH levels in the transgenic plants. Higher reduced states of ascorbate were similarly reported in transgenic poplar trees with overexpressed GR from bacteria (Foyer et al. 1995). Moreover, these results come on line with the recent findings that increased DHAR activity in transgenic potato was not always accompanied by elevation in AsA and other factors might limit AsA accumulation (Goo et al. 2008).

To investigate the stress tolerance of the transgenic potato, all plants were subjected to MV treatment, drought and cadmium stresses. When challenged by MV, transgenic potato plants exhibited less ion leakage compared to NT plants (Fig. 6). Detoxification of various herbicides by GSH conjugation has been demonstrated to be a major factor in herbicide tolerance in maize and other plants (Edwards and Owen 1986, Lamourex and Frear 1979, Gronwald et al. 1987). The enhanced tolerance to MV could be directly linked to the elevated GR activity and the protective effects of the maintained GSH pool. These results are in general agreement with reports that higher GR activity and GSH protect from oxidative stress derived by MV (Aono et al. 1993, 1995, Foyer et al. 1995). Moreover, GSTs are known to function in various cellular processes including their capacity to detoxify herbicides (Hatzios and Hoagland 1989) and protecting cells from oxidative damage by quenching reactive molecules with addition of GSH (McGonigle et al. 2000). Tolerance to MV could also be attributed to higher GST activities in the transgenic potato.

Drought stress accelerates the accumulation of ROS in plant cells. When subjected to drought stress, transgenic potato plants recovered better than NT plants in term of less visual injury on the leaves and stems (Fig. 7). This faster recovery could be attributed to the higher GR activity in transgenic potato. Similarly, up regulation of GR was associated with recovery from drought in tolerant cow pea cultivars (Torres-Franklin et al. 2008). In drought tolerant wheat cultivars, expression level and early induction of GST dur- ing drought was suggested to play a major role in protection of cell optimal metabolism (Galle et al. 2009). Therefore, high GST activity might also counts positively in inducing faster recovery in the transgenic potato.

Under cadmium stress, the growth reduction reflected by the decrease in the length was clearer in roots than for shoots (Fig. 8). Upon entering cells, Cd might be bound by thiolcontaining compounds such as phytochelatin and its precursor, GSH, before being transported to vacuole for storage. Plant GSTs metabolize a wide variety of toxic exogenous compounds (xenobiotic) via GSH conjugation (Mannervik and Daneilson 1988). Accordingly, tolerance to $\mathrm{Cd}$ might rely largely on the availability of protective pools of GSH and on GST activity. In this study, roots were significantly protected in transgenic potato plants compared to NT (Fig. 8), which we assume is directly linked to their higher GSH level and GST activity. In rice seedling exposed to cadmium stress, a significant correlation between applied $\mathrm{Cd}$ level and GSH content or GST activity was observed, and the ability of $\mathrm{Cd}$ detoxification was much higher in roots than in shoots (Chun-hua and Ying 2008).

In conclusion, our results suggest that elevation GSH contents through overexpression of cytosolic GR would significantly contribute in enhancing potato plants tolerance to oxidative stress imposed by MV, drought and cadmium. This approach provides reliable strategy for the development of industrial transgenic potato plants with enhanced tolerance to multiple environmental stresses.

\section{Acknowledgements}

This work was supported by a grant from the Global Center of Excellence for Arid land Sciences of the Arid land Research Center, Tottori University.

\section{Literature Cited}

Alla, M.M.N., A.M. Badawi, N.M.Hassan, Z.M.El-bastawisy and E.G.Badran (2007) Induction of glutathione and glutathioneassociated enzymes in butachlor-tolerant plant species. Am. J. Plant Physiol. 2: 195-205.

Aono,M., A.Kubo, H.Saji, T.Natori, K.Tanaka and N.Kondo (1991) Resistance to active oxygen toxicity of transgenic Nicotiana tabacum that express the gene for glutathione reductase from Escherichia coli. Plant Cell Physiol. 32: 691-697.

Aono,M., A.Kubo, H.Saji, K.Tanaka and N.Kondo (1993) Enhanced tolerance to photooxidative stress of transgenic Nicotiana tabacum with high chloroplastic glutathione reductase activity. Plant Cell Physiol. 34: 129-136.

Aono, M., H.Saji, A.Sakamoto, K. Tanaka, N.Kondo and K. Tanaka (1995) Paraquat tolerance of transgenic Nicotiana tabacum with enhanced activities of glutathione reductase and superoxide dismutase. Plant Cell Physiol. 36: 1687-1691.

Asada, K. and M. Takahashi (1987) Production and scavenging of active oxygen in photosynthesis. In: Kyle, D.J., B. Osmond and C.A.Arntzen (eds.) Photoinhibition, Elsevier, Amsterdam, pp. 227287.

Banerjee,A.K., S.Prat and D.J.Hannapel (2006) Efficient production 
of transgenic potato ( $S$. tuberosum L. ssp andigena) plants via Agrobacterium tumefaciens-mediated transformation. Plant Sci. 170: 732-738.

Bergmann,L. and H.Rennenberg (1993) Glutathione metabolism in plants. In: De Kok,L.J. (ed.) Sulfur Nutrition and Assimilation in Higher Plants, SPB Academic Publishing, The Hague, The Netherlands, pp. 109-123.

Bradford,M.M. (1976) A rapid and sensitive method for the quantitation of microgram quantities of protein utilizing the principle of protein-dye binding. Anal. Biochem. 72: 248-254.

Chun-hua,Z. and G.Ying (2008) Response of glutathione and glutathione S-transferase in rice seedlings exposed to cadmium stress. Rice Sci. 15: 73-76.

Creissen, G., J.Firmin, M.Fryer, B.Kular, N.Leyland, H.Reynolds, G.Pastori, F.Wellburn, N.Baker, A.Wellburn and P.Mullineaux (1999) Elevated glutathione biosynthetic capacity in the chloroplasts of transgenic tobacco plants paradoxically causes increased oxidative stress. Plant Cell 11: 1277-1291.

Edwards, R. and W.J.Owen (1986) Comparison of glutathione Stransferases of Zea mays responsible for herbicide detoxification in plants and suspension-cultured cells. Planta 169: 208-215.

Eltayeb, A.E., N.Kawano, G.H.Badawi, H.Kaminaka, T.Sanekata, I.Morishima, T.Shibahara, S.Inanaga and K. Tanaka (2006) Enhanced tolerance to ozone and drought stresses in transgenic tobacco overexpressing dehydroascorbate reductase in cytosol. Physiol. Plant. 127: 57-65.

Foyer,C.H. and B.Halliwell (1976) The presence of glutathione and glutathione reductase in chloroplasts: a proposed role in ascorbic acid metabolism. Planta 133: 21-25.

Foyer,C.H., M.Lelandais, C.Galap and K.J.Kunert (1991) Effects of elevated cytosolic glutathione reductase activity on the cellular glutathione pool and photosynthesis in leaves under normal and stress conditions. Plant Physiol. 97: 863-872.

Foyer,C.H., N.Souriau, S.Perret, M.Lelandais, K.J.Kunert, C.Pruvost and L.Jouanin (1995) Overexpression of glutathione reductase but not glutathione synthetase leads to increases in antioxidant capacity and resistance to photoinhibition in poplar trees. Plant Physiol. 109: 1047-1057.

Foyer,C.H. and P.M.Mullineaux (1998) The presence of dehydroascorbate and dehydroascorbate reductase in plant tissues. FEBS Lett. 425: 528-529.

Galle,A., J.Csiszar, M.Secenji, A.Gouth, L.Cseuz, I.Tari, J.Györgey and L.Erdei (2009) Glutathione transferase activity and expression patterns during grain filling in flag leaves of wheat genotypes differing in drought tolerance: Response to water deficit. J. Plant Physiol. doi:10.1016/j.jplph.2009.05.016.

Goo, Y.M., H.J.Chun, T.W.Kim, C.H.Lee, M.J.Ahn, S.C.Bae, K.J.Cho, J.A.Chun, C.H.Chung and S.W.Lee (2008) Expressional characterization of dehydroascorbate reductase cDNA in transgenic potato plants. J. Plant. Biol. 51: 35-41.

Griffith,O.W. (1980) Determination of glutathione and glutathione disulfide using glutathione reductase and 2-Viniylrpidine. Anal. Biochem. 106: 207-212.

Gronwald,J.W., E.P.Fuerst, C.V.Eberlein and M.A.Egli (1987) Effect of herbicide antidotes on glutathione content and glutathione-Stransferase activity of sorghum shoots. Pestic. Biochem. Physiol. 29: 66-76.

Hatzios, K.K. and R.E.Hoagland (1989) Crop safeners for herbicides: Development, Uses and Mechanisms of Action, Academic Press Inc, New York, pp.65-101.

Lamoureux,G.L. and D.S.Frear (1979) Pesticide metabolism in higher plants: in vitro enzyme studies. In: Paulson,G.D., D.S.Frear and E.D.Marks (eds.) Xenobiotic Metabolism, ACS Symposium Series 97, American Chemical Society, Washington, DC, pp. 77-128.

Logan, B.A., G. Monteiro, D. Kornyeyev, P.Payton, R.Allen and A.Holaday (2003) Transgenic overproduction of glutathione reductase does not protect cotton, Gossypium hirsutum (Malvaceae), from photoinhibtion during growth under chilling conditions. Am. J. Bot. 90: 1400-1403.

Mannervik,B. and U.H.Daneielson (1988) Glutathione transferases: structure and catalytic activity. CRC Crit. Rev. Biochem.23: 283337.

Marrs, K.A. (1996) The functions and regulations of glutathione $S$ transferases in plants. Annu. Rev. Plant Physiol. Plant Mol. Bio. 47: $127-158$.

Marty, L., W. Siala, M. Schwarzländer, M.D. Fricker, M. Wirtz, L.J.Sweetlove, Y.Meyer, A.J.Meyer, J.Reichheld and R.Hell (2009) The NADPH-dependent thioredoxin system constitutes a functional backup for cytosolic glutathione reductase in Arabidopsis. Proc. Natl. Acad. Sci. USA 106: 9109-9114.

Mauch,F. and R.Dudler (1993) Differential induction of distinct glutathione-S-transferases of wheat by xenobiotics and by pathogen attack. Plant Physiol. 102: 1193-1201.

McGonigle,B., S.J.Keeler, S.M.C.Lau, M.K.Koeppe and D.P.Okeefe (2000) A genomic approach to the comprehensive analysis of the glutathione S-transferase gene family in soybeen and maize. Plant Physiol. 124: 1105-1120.

Mittler,R. (2002) Oxidative stress, antioxidants and stress tolerance. Trends Plant Sci. 7: 405-410.

Morell,S., H.Follmann, M.DeTullio and I.Häberlein (1997) Dehydroascorbate and dehydroascorbate reductase are phantom indicators of oxidative stress in plants. FEBS Lett. 414: 567-570.

Murashige, T. and F.Skoog (1962) A revised medium for rapid growth and bioassays with tobacco tissue cultures. Physiol. Plant. 15: 473497.

Nakagawa, T., T.Suzuki, S.Murata, S.Nakamura, T.Hino, K.Maeo, R.Tabata, T.Kawai, K. Tanaka, Y.Niwa et al. (2007) Improved gateway binary vectors: high-performance vectors for creation of fusion constructs in transgenic analysis of plant. Biosci. Biotech. Biochem. 71: 2095-2100.

Noctor, G., A.C.M.Arisi, L.Jouanin, K.J.Kunert, H.Rennenberg and C.H.Foyer (1998) Glutathione: biosynthesis, metabolism and relationship to stress tolerance explored in transformed plants. J. Exp. Bot. 49: 623-647.

Noctor,G. and C.H.Foyer (1998) Ascorbate and glutathione: keeping active oxygen under control. Annu. Rev. Plant Physiol. Plant. Mol. Biol. 49: 249-279.

Perl,A., R.Perl-Treves and S.Dalili (1993) Enhanced oxidative stress defense in transgenic potato expressing $\mathrm{Cu}, \mathrm{Zn}$ superoxide dismutase. Theor. Appl. Genet. 85: 568-576.

Ohashi, Y. and M.Matsuoka (1985) Synthesis of stress proteins in tobacco leaves. Plant Cell Physiol. 26: 473-480.

Pilon-Smits, E.A.H., Y.L.Zhu, T.Sears and N. Terry (2000) Overexpression of glutathione reductase in Brassica juncea: Effects on cadmium accumulation and tolerance. Physiol. Plant. 110: 455460 .

Potters, G., L.DeGara, H.Asard and N.Horemans (2002) Ascorbate and glutathione: guardians of the cell cycle, partners in crime? Plant Physiol. Biochem. 40: 537-548.

Potters, G., N.Horemans, S.Bellone, R.J.Caubergs, P.Trost, Y.Guisez and H.Asard (2004) Dehydroascorbate influences the plant cell cycle through a glutathione-independent reduction mechanism. Plant 
Physiol. 134: 1479-1487.

Shigeoka, S., T.Onishi, Y.Nakano and S.Kitaoka (1987) Change of Lascorbic acid content in Synchronized cultures of Euglena gracilis. J. Gen. Microbiol. 133: 221-225.

Tanaka,K., H.Saji and M.Kondo (1988) Immunological properties of spinach glutathione reductase and inductive biosynthesis of the enzyme with ozone. Plant Cell Physiol. 29: 637-642.

Tang, L., S.K. Kwon， S.H. Kim， J.S. Kim， J.S. Choi， K.Y.Cho, C.K.Sung, S.S.Kwak and H.S.Lee (2006) Enhanced tolerance of transgenic potato plants expressing both superoxide dismutase and ascorbate peroxidase in chloroplasts against oxidative stress and high temperature. Plant Cell Rep. 25: 1380-1386.

Tang, L., M.D. Kim, K.S. Yang, S.Y.Kown, S.H.Kim, J.S. Kim, D.J.Yun, S.S.Kwak and H.S.Lee (2008) Enhanced tolerance of transgenic potato plants overexpressing nucleoside disphosphate kinase 2 against multiple environmental stresses. Transgen. Res. 17: 705-715.

Torres-Franklin,M.L., D.Contour-Ansel, Y.Zuily-Fodil and A.PhamThi (2008) Molecular cloning of glutathione reductase cDNAs and analysis of GR gene expression in cowpea and common bean leaves during recovery from moderate drought stress. J. Plant Physiol. 165: 514-521.

Trümper,S., H.Follmann and I.Häberlein (1994) A novel dehydroascorbate reductase from spinach chloroplasts homologous to plant trypsin inhibitor. FEBS Lett. 352: 159-162.

Tzafrir,I., R. Pena-Muralla，A.Dickerman, M. Berg, R. Rogers, S. Hutchens, T.C.Sweeney, J.McElver, G.Aux, D.Patton and D. Meinke (2004) Identification of genes required for embryo development in Arabidopsis. Plant Physiol. 135: 1206-1220.

Wagner,U., R.Edwards, D.P.Dixon and F.Mauch (2002) Probing the diversity of the Arabidopsis glutathione S-transferases gene family. Plant Mol. Biol. 49: 515-532.

Wells, W.W., D.P.Xu, Y.Yanf and P.A.Rocque (1990) Mammalian thioltransferase (glutaredoxin) and protein disulfide isomerase have dehydroascorbate reductase activity. J. Biol. Chem. 265: 15361-15364.

Xiang,C., B.L.Werner, E.M.Christensen and D.J.Oliver (2001) The biological functions of glutathione revisited in arabidopsis transgenic plants with altered glutathione levels. Plant Physiol. 126: 564-574.

Yu,D., Z.Xie, C.Chen, B.Fan and Z.Chen (1999) Expression of tobacco class II catalase gene activates the endogenous homologous gene and is associated with disease resistance in transgenic potato plants. Plant Mol. Bio. 39: 477-488.

Zimmermann, P., M.Hirsch-Hoffmann, L.Hennig and W.Gruissem (2004) GENEVESTIGATOR. Arabidopsis microarray database and analysis toolbox. Plant Physiol. 136: 2621-2632. 